ABDI: Jurnal Pengabdian dan Pemberdayaan Masyarakat ISSN: 2656-369X (Print), 2684-8570 (Online)

Volume 2 No. 2, Desember 2020

http://abdi.ppj.unp.ac.id/index.php/abdi

Email: abdi@ppj.unp.ac.id

DOI: https://doi.org/10.24036/abdi.v2i2.47

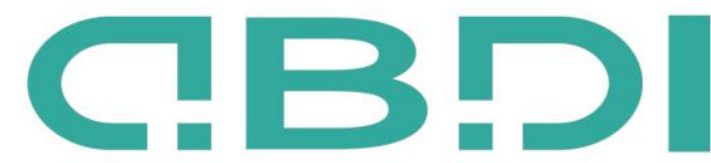

ABDI: JURNAL PENGABDIAN DAN PEMBERDAYAAN MASYARAKAT

\title{
Pengembangan Objek Wisata Berbasis Ekowisata dalam Meminimalisir Pembuangan Sampah Sembarangan di Pantai Kabupaten Bangka Selatan
}

\section{Aryanto Ariyanto ${ }^{1}$, Ligi Agista ${ }^{2}$, Henita ${ }^{3}$, Neneng Neneng ${ }^{4}$, Putri Izati Yasidah ${ }^{5}$, Rizki Amelia ${ }^{6}$, Rosida Rahmawati ${ }^{7}$, Saryatul Amani ${ }^{8}$, Dedy Putranto ${ }^{9}$}

STKIP Muhammadiyah Bangka Belitung

Email: putriajr221@gmail.com

\begin{abstract}
Abstrak
Kebanyakan masyarakat masih memahami sampah sebagai barang yang tidak diinginkan dan tidak berguna sehingga harus cepat dibuang. Persepsi masyarakat mengenai sampah inilah yang menjadikan sampah hanya berpindah tempat dan akhirnya menumpuk pada satu tempat saja, misalnya tempat pembuangan akhir (TPA). Tujuan dari kegiatan pengabdian masyarakat adalah untuk memanfaatkan lokasi pantai yang ada di Kampung Nelayan sebagai objek wisata bagi Masyarakat Kampung Nelayan RT 01 RW 02 serta meminimalisir pembuangan sampah sembarangan di Pantai Nelayan. Pantai tersebut kurang diminati oleh masyarakat sekitar, dan sangat jarang dikunjungi karena belum tersedianya objek wisata. Untuk mengatasi permasalahan yang ada di Kampung Nelayan metode yang dilakukan adalah perbaikan pantai dengan memanfaatkan pantai Nelayan sebagai objek wasata yang berbasis ekowisata bagi masyarakat. Program ini dibuat untuk menciptakan suasana pantai agar terlihat indah dan asri agar bisa menarik minat pengunjung yang akan datang dengan fasilitas yang telah disediakan yaitu berupa ayunan,spot foto, dan kursi santai. Hasil dari pengabdian masyarakat ini dilihat dari jumlah pengunjung sebelum dilakukan pengembangan objek wisata tersebut kurang diminati dan setelah dilakukan pengembangan objek wisata masyarakat lebih banyak mengunjungi pantai Kampung Nelayan pada saat sore hari untuk menikmati sunset serta mengajak anak-anaknya bermain dengan fasilitas yang telah tersedia.

Kata Kunci: Objek Wisata, Ekowisata

\section{Abstract}

Most people still understand rubbish as an unwanted and useless item that must be quickly disposed of. This public perception of rubbish is what makes rubbish only move places and eventually pile up in one place, for example a landfill (TPA). The purpose of community service activities is to take advantage of the location of the beach in the Fishermen's Village as a tourist attraction for the Village of the Fishermen's Community RT 01 RW 02 and to minimize littering at the Fisherman Beach. The beach is less attractive to the surrounding community, and very rarely visited because of the unavailability of attractions. To overcome the problems that exist in the Village of Fishermen the method used is to improve the beach by utilizing the Fishermen's beach as an object of ecotourism-based wasata for the community. This program was created to create a beach atmosphere to look beautiful and beautiful in order to attract the interest of visitors who will come with the facilities that have been provided in the form of swings, photo spots, and lounge chairs. The results of this community service can be seen from the number of visitors before the development of the tourist attraction is less desirable and after the development of tourism objects, more people visit the coast of the Fisherman Village in the afternoon to enjoy the sunset and invite their children to play with the facilities that are available.
\end{abstract}

Keywords: Tourism Object, Ecotourism

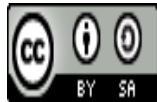




\section{Pendahuluan}

Bangsa yang maju adalah bangsa yang berbudaya. Indonesia adalah bangsa yang kaya akan aneka ragam budaya. Budaya-budaya yang telah diwariskan dari para leluhur seperti bangsa yang melahirkan generasi dengan membiasakan membuang sampah pada tempatnya. Pengembangan obyek wisata merupakan penggerak utama sektor kepariwisataan membutuhkan kerjasama seluruh pemangku kepentingan yang terdiri dari masyarakat dan pemerintah,kerjasama langsung dari kalangan usaha maupun dari pihak swasta. (Devy \& Soemanto, 2017). Sampah sudah menjadi masalah umum yang dialami oleh masyarakat di Indonesia khususnya di Bangka Belitung. Kebanyakan masyarakat masih memahami sampah sebagai barang yang tidak diinginkan dan tidak berguna sehingga harus cepat dibuang.

Persepsi masyarakat mengenai sampah inilah yang menjadikan sampah hanya berpindah tempat dan akhirnya menumpuk pada satu tempat saja, misalnya tempat pembuangan akhir (TPA). Apabila sampah tidak diolah dengan baik maka akan berdampak pada masalah kesehatan dan juga kerusakan lingkungan bahari (Nur, 2016). Dalam konteks pengembangan kawasan-kawasan bahari harus dikaitkan dengan berbagai kepentingan yang mendasar, yaitu pemberdayaan masyarakat pesisir. Masyarakat pesisir adalah masyarakat yang memiliki banyak pengetahuan tentang kondisi obyektif wilayahnya, oleh karena itu dalam pengembangan kawasan objek wisata, senantiasa hendaknya dimulai pendekatan terhadap masyarakat setempat sebagai suatu model pendekatan perencanan partisipatif yang menempatkan masyarakat pesisir memungkinkan meningkatkan dan menganalisa pengetahuan mereka tentang bahari dan kehidupan pesisir, membuat rencana dan bertindak.

Pengambangan objek wisata di pantai untuk masyarakat pesisir lebih menekankan pada pemberdayaan masyarakat untuk pembiasaan membuang sampah pada tempatnya yang dapat meminimalisir pembuangan sampah pada pesisir pantai. Dalam pengembangan objek wisata tujuan yang ingin dicapai adalah agar masyarakat lebih menyadari untuk tidak membuang sampah pada lingkungan sekitar pantai yang menyebabkan kerusakaan pada pantai serta menyebabkan banjir pada pemukiman penduduk di sekitar pantai. Oleh karena itu dalam rangka pengelolaan objek wisata diharapkan dapat meningkatkan sumber daya alam dan sumber daya buatan secara berdayaguna, untuk meningkatkan kualitas sumber daya manusia serta mencegah dan menanggulangi dampak negatif dari pembuangan sampah sembarangan (Fahrina, 2011).

Posisi sektor parawisata Kabupaten Bangka Selatan sangat penting di untuk dikembangkan. Pengembangan objek wisata di Pantai Kampung Nelayan diharapkan dapat menjadi tujuan wisata, upaya pengembangan objek wisata merupakan trobosan untuk mengembangkan parawisata di Kabupaten Bangka Selatan. Selain itu diharapkan juga untuk dapat meningkatkan kehidupan sosial ekonomi masyarakat yang dapat dikembangkan dan dapat dikenalkan pada daerah lainnya yang dapat menjadi ciri khas dari Kampung Nelayan tersebut, antara lain pemasaran produk-produk industri kecil seperti terasi, ikan asin, teritib dari hasil lautnya. Pengembangan objek wisata di Pantai Kampung Nelayan merupakan suatu perencanaan yang diwujudkan dengan penataan kembali lingkungan dan fasilitas-fasilitas yang telah ada serta penambahan fasilitas-fasilitas baru yang diharapkan dapat mewadahi aktivitas kawasan pantai sebagai objek wisata.

Berdasarkan hasil pengamatan dan observasi di Kampung Nelayan, permasalahan yang terjadi dilapangan bahwa sampah yang muncul diakibatkan oleh pembuangan sampah rumah tangga dan hasil kiriman dari kampung sebelah melalui selokan yang pembuangan sampahnya menuju pantai, maka dari itu akibat dari pembuangan sampah ini menyebabkan pantai menjadi kotor dan penuh dengan sampah, apalagi jika hujan turun sampah semakin banyak dan menyumbat saluran air selokan hingga menyebabkan banjir disekitar dirumah warga setempat. Berdasarkan permasalahan tersebut solusi yang dapat kami berikan adalah 1). Sebelum mengajak masyarakat kampung Nelayan membersihkan pantai kami yang terlebih dahulu melakukan gotong royong di pantai. 2). Setelah melakukan pendekatan bersama masyarakat kampung Nelayan kami mengajak masyarakat untuk mengambil sampah yang berserakan di pantai dan membuangnya pada bak sampah yang sudah disediakan.

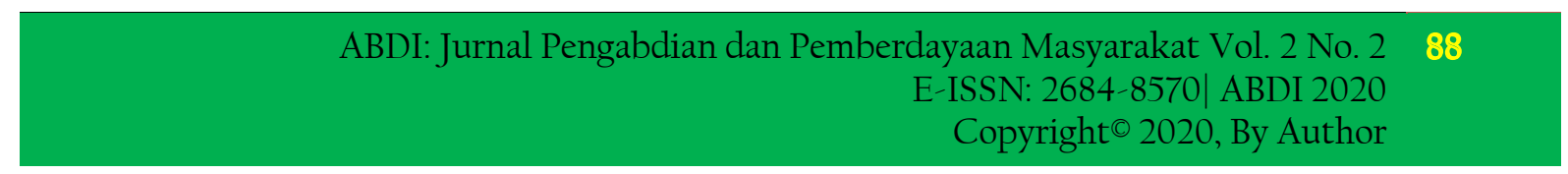


Tujuan dari kegiatan pengabdian masyarakat adalah untuk memanfaatkan lokasi pantai yang ada di Kampung Nelayan sebagai objek wisata berbasis ekowisata bagi Masyarakat Kampung Nelayan RT 01 RW 02 serta meminimalisir pembuangan sampah sembarangan di Pantai Nelayan.

\section{Tabel 1. Hasil Wawacara Bersama Ketua RT dan Masayarakat}

\begin{tabular}{ll}
\hline \multicolumn{1}{c}{ Narasumber } & \multicolumn{1}{c}{ Pendapat } \\
\hline Ketua RT & Untuk pembiasan membuang sampah pada tempatnya di Kampung Nelayan \\
& masih kurang, tekadang masyarakat di pesisir pantai masih sering \\
& membuang sampah ke pantai akibatnya pada saat air surut sampah banyak, \\
& masalah lainnya pada saat hujan turun sampah kiriman dari kampung lainya \\
& langsung terbawa arus air ke Kampung Nelayan melalui selokan yang \\
& mengarah langsung ke pantai. Untuk pengangkutan sampah oleh PEMDA \\
& juga belum rutin, terkadang 4-5 hari sekali, yang menyebabkan sampah \\
& menumpuk di tempat sampah yang telah disediakan. \\
\hline Masyarakat & Biasanya kita membuang sampah dengan cara dilepar langsung kelaut, \\
& karena sampah itu akan hanyut, atau dengan mengumpulkan sampah \\
& terlebih dahulu lalu dibakar, memang ada tempat sampah dari pemerintah, \\
& tetapi tidak setiap rumah mendapatkannya itu pun 3 rumah mendapatkan 1 \\
& tempat sampah, pengangkutan sampah juga tidak rutin. Sehingga kami \\
& lebih memilih membuang langsung kelaut ataupun langsung dibakar. \\
\hline
\end{tabular}

Tahapan pengumpulan data yang kami lakukan dalam pelaksanaan kegiatan tersebut adalah:

1. Melakukan observasi awal di Kampung Nelayan selama satu hari pada tanggal 8 Januari 2020.

2. Melakukan observasi yang kami lakukan pada tanggal 28 Januari 2020.

3. Proses pengumpulan data yang kami lakukan adalah wawancara langsung ketua RT dan Masyarakat setempat.

Sasaran kgiatan ini adalah masyarakat Kampung Nelayan dimulai dari anak-anak hingga dewasa. Mereka mempunyai keinginan untuk berpartisipasi dalam membuat program yang telah kami rencanakan.

\section{Metode Pelaksanaan}

Metode dalam pengabdian masyarakat ini adalah pengembangan objek wisata antara lain:

1. Pembuatan ayunan, pembuatan ayunan dimulai pada tanggal 04 Januari-16 Februari 2020, pertamatama yang dilakukan dalam membuat ayanan adalah dengan membuat kerangka ayunan terlebih dahulu, dilanjutan dengan membuat pondasi ayunan, pengecoran tiang ayunan dan plester pondasi ayunan, selanjutnya pemasangan tali ayunan, dan terakhir pengecatan ayunan.

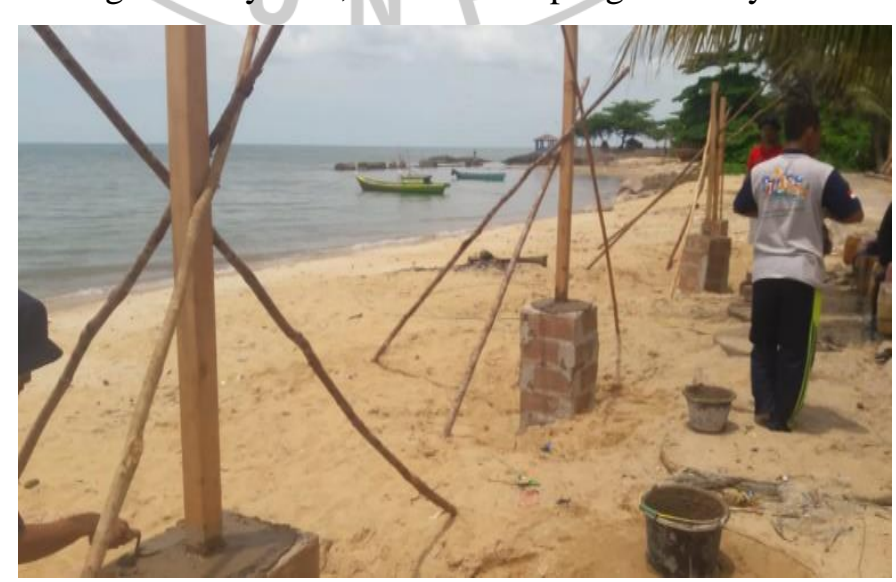

Gambar 1. Pembuatan ayunan

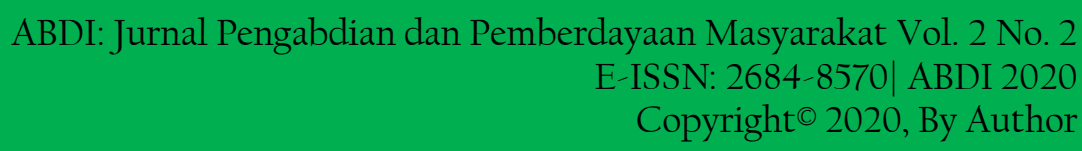


Ariyanto Aryanto, dkk.

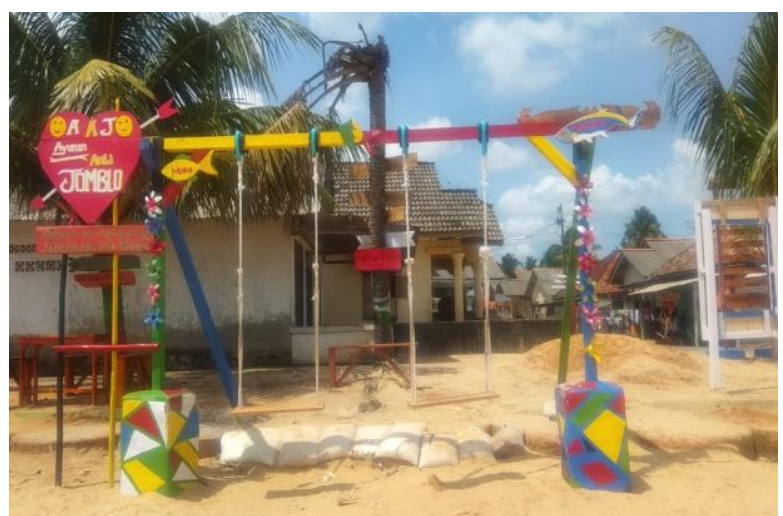

Gambar 2. Ayunan yang telah dibuat

2. Sport foto, sport foto terdiri dari beberapa macam antara lain bingkai foto sunset, bingkai foto instagram, dan gapura kata-kata.

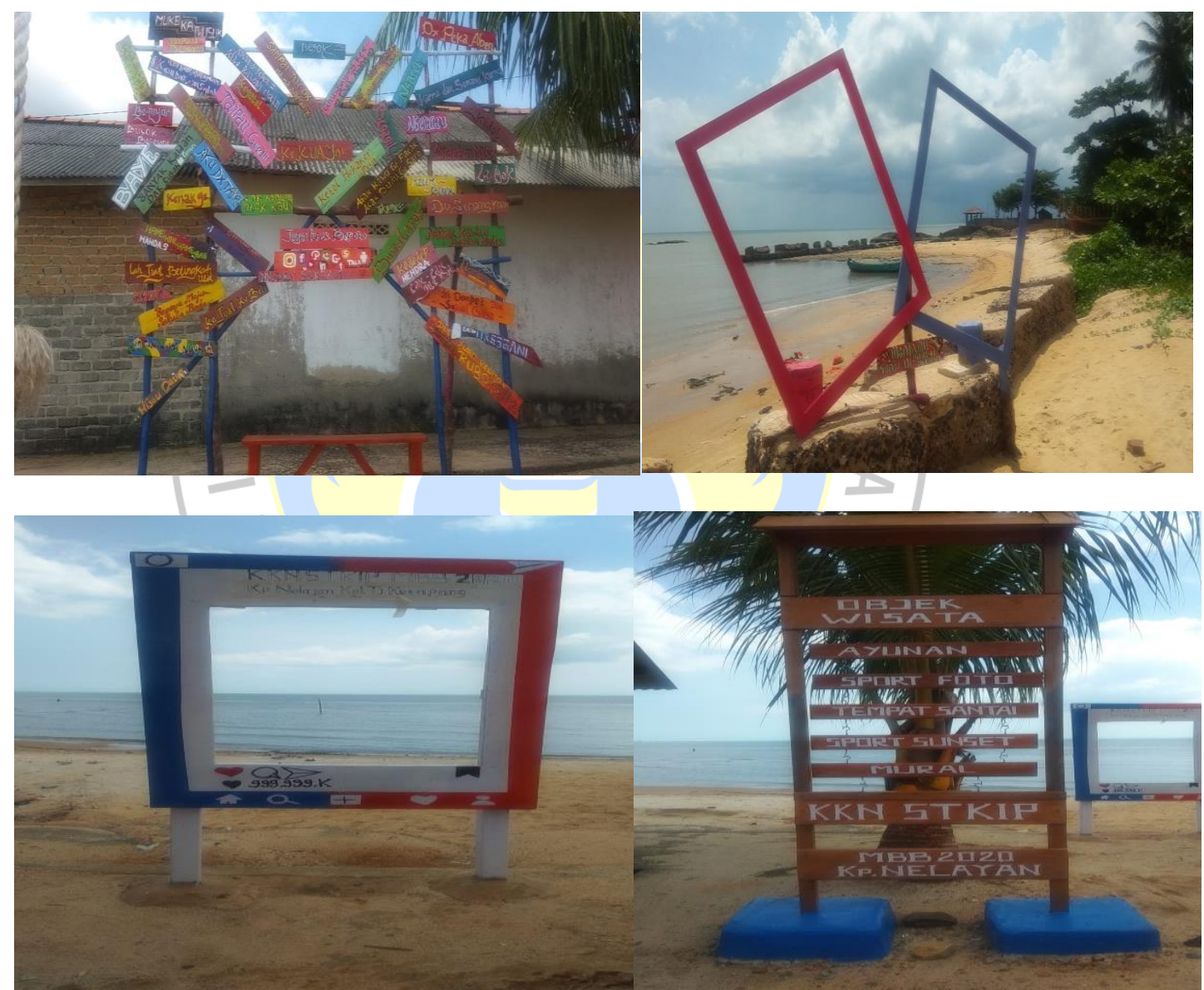

Gambar 3. Sport Foto 
3. Mural, mural dibuat dengan memanfaatkan tembok gazebo yang sebelumnya hanya di cat saja, dari sinilah kami berinisiatif membuat mural.

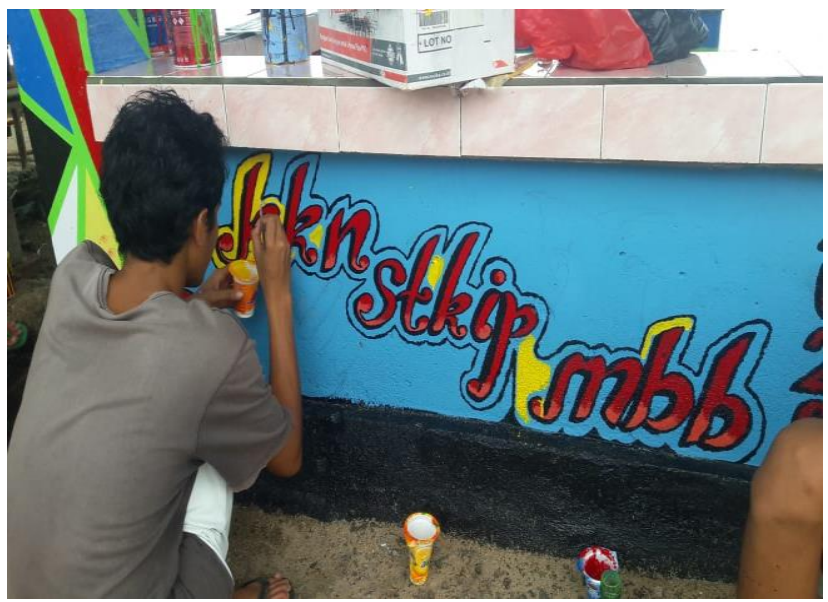

Gambar 4. Mural

4. Kursi santai, kursi santai dibuat dengan tujuan menambah fasilitas yang ada di Pantai Kampung Nelayan agar disaat pengunjung datang bisa duduk santai di kursi tersebut.

Untuk meminimalisir pembuangan sampah ke Pantai kami melakukan beberapa cara yaitu praktek langsung dalam kegiatan pembersihan sampah di pantai serta mengajak masyarakat sekitar pantai untuk tidak membuang sampah ke pantai dan membiasakan masyarakat dalam membuang sampah pada tempatnya. Selanjutnya memberikan sosialisasi kepada anak-anak agar membiasakan untuk membuang sampah pada tempatnya, hal ini bertujuan untuk menjaga kebersihan lingkungan yang disekitar khususnya di Pantai Nelayan.

\section{Hasil dan Pembahasan}

Berdasarkan hasil pengabdian yang dilakukan menggunakan metode pengembangan objek wisata. Hasil wawancara awal yang dilakukan pada ketua RT mengenai pantai dikampung Nelayan tersebut kurang diminati masyarakat sekitar, dan jarang di kunjungi. Berdasarkan observasi awal pengabdian pertama-tama melihat lingkungan yang ada di sekitar pantai. Pantai Kampung Nelayan merupakan pantai yang belum memiliki identitas. Karena pantai tersebut kurang terawat dan masih banyak sampah yang dibuang secara sengaja maupun kiriman dari selokan yang berakhir menuju pantai.

Sehingga menyebabkan pantai Nelayan kurang diminati pengunjung karena belum dikenali dan masyarakat sekitar mengelola pantai tersebut hanya untuk mencari nafkah. Dilihat dari permasalahan diatas dapat diambil tindakan untuk mengelola pantai dengan cara pengembangan objek wisata berbasis Ekowisata dalam meminimalisir pembuangan sampah sembarangan di Pantai Kabupaten Bangka Selatan. Tindakan dilakukan dengan cara membersihkan pantai, membuat ayunan, spot foto, kursi santai, dan kata-kata di pantai agar terlihat lebih indah dan asri untuk menarik pengunjung. Sehingga penulis melakukan perbaikan lingkungan pantai Kampung Nelay an ini menjadi pantai yang layak untuk dikunjungi, agar dapat dikenal oleh masyarakat Toboali dan sekitarnya untuk menikmati suasana pantai yang indah dan asri, serta dapat menikmati keindahan senja disore hari.

Pada saat dilakukannya kegiatan pandangan masyarakat tentang membuang sampah sembarangan sudah mulai berubah, terlihat masyarakat lebih memilih mengumpulkan sampah dipinggir pantai lalu dibakar dibandingkan dengan membuang langsung ke pantai, hal ini dikarenakan pengabdi memberikan beberapa saran untuk masyarakat agar tidak membuang sampah langsung kepantai, agar tidak mengganggu ekosistem yang ada dipantai Kampung Nelayan. Dilihat dari jumlah pengunjung sebelum dilakukan perbaikan pantai tersebut kurang diminati dan setelah dilakukan perbaikan pantai ini lebih banyak yang mengunjungi pantai Kampung Nelayan pada saat sore hari untuk menikmati

$$
\begin{array}{r}
\text { ABDI: Jurnal Pengabdian dan Pemberdayaan Masyarakat Vol. } 2 \text { No. } 2 \\
\text { E-ISSN: 2684-8570| ABDI } 2020 \\
\text { Copyright` } 2020 \text {, By Author }
\end{array}
$$


sunset serta mengajak anak-anaknya bermain dengan fasilitas yang telah tersedia. Dampak positif dari ekowisata sendiri menurut Emma Hijriati dan Rina Mardiana (2014) 1) menciptakan kesempatan berusaha, 2) meningkatkan kesadaran masyarakat mengenai pemafaatan objek wisata, 3) menigkatkan upaya pelestarian lingkungan dan, 4) meningkatnya promosi penggunaan sumber daya alam secara berkelanjutan. Dari dampak tersebut, ada beberapa yang sudah dirasakan masyrakat Kampung Nelayan antara lain, pemanfaatan objek wisata, kesadaran masyrakat dalam pelestarian lingkungan pantai, dan pendapatan ekonomi masyrakat disekitar pantai yang berjualan beranekaragam jajanan makanan.

Melalui ekowisata di pantai Nelayan, seluruh masyarakat kampung Nelayan bersama-sama membangun ekowisata dengan memperhatikan aspek lingkungan.Dengan dibukanya menjadi kawasan wisata, perlu adanya perubahan bagaimana cara mengelola kawasan yang dahulunya kampung biasa menjadi kawan ekowisata yang nantunya akan sering dikunjungi wisatawan yang keluar kampung Nelayan. Menurut Murianto dan Lalu Masyhudi (2018) pergeseran konsep keparawisataan saat ini menuju ekowisata merupakan peluang besar bagi wilayah dengan potensi alam. Hal ini terjadi karena kecederungan semakin banyaknya wisatawan yang mengunjungi objek yang berbasis alam, budaya dan penduduk lokal.

Ekowisata berbasis masyarakat merupakan usaha ekowisata yang menitikberaatkan peran aktif masyarakat. Hal tersebut didasarkan kepada kenyataan bahwa masyarakat memiliki pengetahuan tentang alam serta budaya yang menjadi potensi dan nilai jual sebagai daya tarik wisata, sehingga pelibatan masyarakat menjadi mutlak. Pola ekowisata berbasis masyarakat mengakui hak masyarakat lokal dalam mengelola kegiatan wisata di kawasan yang mereka miliki secara adat ataupun sebagai pengelola. Dengan adanya pola ekowisata berbasis masyarakat bukan berarti masayarakat menjalankan usaha ekowisata sendiri. Apabila banyak pengunjung yang datang pada pantai Kampung Nelayan secara tidak langsung dapat meningkatkan pendapatan asli daerah itu sendiri. Selain itu masyarakat di sekitar ekowisata dapat memperoleh keuntugan karena adanya lapangan pekerjaan yang akan meningkatkan pendapatan kesejahteraan masyarakat sekitar. (Ferdinan, dkk. 2010)

Berdasarkan Peraturan Menteri Dalam Negeri Nomor 33 Tahun 2009 bahwa prinsip pengembangan ekowisata meliputi:

1. Kesuaian, antara jenis dan karakteristik ekowisata

2. Konservasi, yaitu melindungi, mengawetkan, dan memanfaatkan secara lestari sumber daya alam yang digunakan untuk ekowisata

3. Ekonomis, yaitu memberikan manfaat untuk masyarakat setempat dan menjadi penggerak pembangunan ekonomi diwilayahnya serta memastikan usaha ekowisata dapat berkelanjutan

4. Edukasi,yaitu mengandung unsur pendidikan untuk mengandung persepsi seseorang agar memilki kepedulian, tanggung jawab, ddan komitmen terhadappelestarian lingkungan dan budaya.

5. Memberikan kepuasan dan pengalaman kepada pengunjung

6. Partisipasi masyarakat, yaitu peran serta masyarakat dalam kegiatan perencanaan, pemanfaatan, dan pegendalian ekowisata dengan menghormati nilai-nilai social budaya dan keagamaan masyarakat disekitar kawasan dan

7. Menampung kearifan lokal (Hijriati \& Mardiana, 2014)

\section{Kesimpulan}

Dapat ditarik kesimpulan hasil akhir dari kegiatan pengabdian observasi dilakukan secara langsung turun kelapangan untuk melihat kondisi yang ada di Kampung Nelayan. Upaya yang dilakukan untuk menarik pengunjung agar datang ke Pantai Nelayan upaya yang kami lakukan adalah dengan membersihkan pantai, membuat ayunan, spot foto dan kata-kata di pantai agar terlihat lebih indah dan asri. Harapan kegiatan ini dibuat agar Pantai Nelayan tersebut dikenali oleh masyarakat Toboali dan sekitarnya melalui perbaikan lingkungan pantai dan pengembangan objek wisata yang telah kami lakukan, sehingga program-program yang direncanakan dapat terrealisasi dengan baik dan dapat diselesaikan tepat waktu.

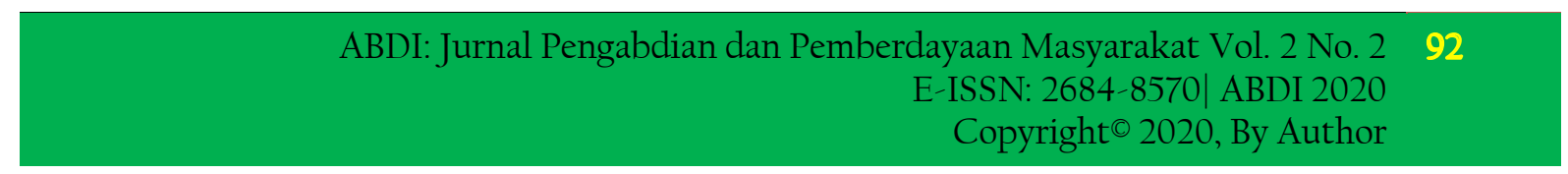




\section{Daftar Pustaka}

Attar, M., Hakim, L., \& Yanuwiadi, B. (2013). Analisis potensi dan arahan strategi kebijakan pengembangan desa ekowisata di Kecamatan Bumiaji-Kota Batu. Journal of Indonesian Tourism and Development Studies, 1(2), 68-78.

Devy, H.A. \& Soemanto, R.B. (2017). Pengembangan Obyek dan Daya Tarik Wisata Alam Sebagai Daerah Tujuan Wisata Alam Sebagai Daerah Tujuan Wisata Di Kabupaten Karangnyar. Jurnal Sosiologi Dilema, 32(1), 34-44.

Fahrina, A. (2011). Penataan Kawasan Objek Wisata Pantai Baloiya Kecamatan Bontosikuyu Kabupaten Kepulauan Selayar. Skripsi. Universitas Islam Negeri Alauddin Makassar.

Ferdinan, F (2010). Pengembangan Wisata Alam Berbasis Ekowisata Dalam Perspektif Pelayana Publik. Jurnal Administrasi Publik, 3 (12), 2123-2127.

Hijriati, E, \& Mardiana, R. (2014). Pengaruh Ekowisata Berbasis Masyarakat Terhadap Perubahan Kondisi Ekologi, Sosial dan Ekonomi di kampung Batusuhunan, Sukabumi, Jurnal Sosiologi Pedesaan, 1(1), 146-159.

Irawan, H. (2018). Pengembangan Ekowisata Bahari Berbasis Keankaragaman Hayati Pada Kelompok Sadar Wisata (Pokdarwis) Pengudang Bintan Mangrove Di Desa Pengudang Kabupaten Bintan. Pengkemas Maritim, 1(1), 1-9.

Murianto, M, \& Masyhudi, L. (2018). Strategi Pengembangan Ekowisata Berbasis Masyarakat di Teluk Seriwe Lombok Timur. Jurnal Media Bina Ilmiah, 13 (2), 913-924.

Nur, M \& Masyrukan, M. (2016). Penanganan Sampah Organik dengan Bak Sampah Komposter di Dusun Susukan Kelurahan Susukan Kecamatan Susukan Kabupaten Semarang'. Jurnal WARTA, 19 (1), 74-82.

Satria, D. (2009). Strategi pengembangan ekowisata berbasis ekonomi lokal dalam rangka program pengentasan kemiskinan di wilayah Kabupaten Malang. Journal of Indonesian Applied Economics, 3(1), 25-33

Zulia, M., Supratman, O., \& Sari, S. P. (2019). Kesesuaian Dan Daya Dukung Ekowisata Mangrove di Desa Kurau dan Desa Kurau Barat Kabupaten Bangka Tengah. Akuatik: Jurnal Sumberdaya Perairan, 13(2), 94-104.

\section{ABDI: Jurnal Pengabdian dan Pemberdayaan Masyarakat Vol. 2 No. 2

